\title{
Kajian Teologis Kepemimpinan Musa
}

\author{
Ronald Sianipar, ${ }^{1 *}$ Irfan Feriando Simanjuntak ${ }^{2}$, Aprilius Nahak ${ }^{3}$, George Julianus Samaran ${ }^{4}$ \\ Prodi Teologi, STT Real Batam \\ Prodi Teologi, STT Real Batam \\ Prodi Teologi, STT Real Batam \\ Prodi Teologi, STT Real Batam \\ sianiparamos@gmail.com
}

\begin{abstract}
A good leader is a leader who has the ability to influence others to follow him. A good leader is also true is a leader who comes from God or a leader chosen by God. Same is the case with Christian leaders. A Christian leader is someone who has the awareness that only Jesus is the true Leader, can make a Christian leader successfully facing pressure and difficulties. what is the attitude of the leader in facing difficulties and pressures, according to the Bible's perspective A Christian leader is required not only to be able to look positively at every difficulty, avoid tension, control anger, but every leader is also expected to have patience, love everyone who is led, seek friendship, and can emulate Jesus Christ. Moses was one of the great leaders of the Old Testament. His action in the world of leadership is obtained from every life experience that requires him to always learn. Moses' life experience became God's instrument to form and reveal His plan to Moses, that He intended to make Moses a great leader who drove the Israelites out of the land of slavery. God chose Moses to be a leader not only because of his abilities; God also intended to equip Moses with the spirit of not giving up easily, an important condition needed by every great leader.
\end{abstract}

Keywords: Leadership, Moses

\begin{abstract}
Abstrak
Pemimpin yang baik adalah pemimpin yang mempunyai kemampuan untuk mempengaruhi orang lain untuk mengikutinya. Pemimpin yang baik juga benar adalah pemimpin yang datang dari Tuhan atau pemimpin yang dipilih oleh Tuhan. Sama halnya dengan pemimpin Kristen. Seorang pemimpin Kristen adalah seorang yang memiliki kesadaran bahwa hanya Yesuslah Pribadi Pemimpin yang benar, dapat membuat pemimpin Kristen berhasil menghadapi tekanan dan kesulitan. bagaimana sikap pemimpin dalam menghadapi kesulitan dan tekanan, sesuai dengan sudut pandang Alkitab. Seorang pemimpin Kristen dituntut tidak hanya bisa memandang positif setiap kesulitan yang ada, menghindari ketegangan, mengontrol amarah, namun setiap pemimpin juga diharapkan memiliki kesabaran, mengasihi tiap-tiap orang yang dipimpin, mengusahakan persahabatan, dan dapat meneladani Yesus Kristus. Musa adalah salah seorang pemimpin besar dalam Perjanjian Lama. Sepak terjangnya dalam dunia kepemimpinan diperolehnya dari setiap pengalaman hidup yang menuntutnya untuk selalu belajar. Pengalaman hidup Musa menjadi alat Tuhan untuk membentuk dan menyatakan rencana-Nya kepada Musa, bahwa Ia bermaksud menjadikan Musa seorang pemimpin besar yang mengantarkan bangsa Israel keluar dari tanah perbudakan. Allah memilih Musa menjadi pemimpin bukan hanya karena kecakapannya; Allah juga bermaksud memperlengkapi Musa dengan semangat tidak mudah menyerah, syarat penting yang dibutuhkan oleh setiap pemimpin besar.

Kata kunci: Kepemimpinan, Musa
\end{abstract}




\section{PENDAHULUAN}

Pemimpin yang baik adalah pemimpin yang mempunyai kemampuan untuk mempengaruhi orang lain untuk mengikutinya. Pemimpin yang baik juga benar adalah pemimpin yang datang dari Tuhan atau pemimpin yang dipilih oleh Tuhan. Sama halnya dengan pemimpin Kristen. Seorang pemimpin Kristen adalah seorang yang memiliki kesadaran bahwa hanya Yesuslah Pribadi Pemimpin yang benar, dapat membuat pemimpin Kristen berhasil menghadapi tekanan dan kesulitan. bagaimana sikap pemimpin dalam menghadapi kesulitan dan tekanan, sesuai dengan sudut pandang Alkitab. Seorang pemimpin Kristen dituntut tidak hanya bisa memandang positif setiap kesulitan yang ada, menghindari ketegangan, mengontrol amarah, namun setiap pemimpin juga diharapkan memiliki kesabaran, mengasihi tiap-tiap orang yang dipimpin, mengusahakan persahabatan, dan dapat meneladani Yesus Kristus.

Dalam penelitian ini penulis tidak sedang membahas tentang kepemimpinan Kristen, tetapi membahas tentang studi kepemimpinan Musa, bagaimana Musa dipanggil dan diutus oleh Tuhan untuk membebaskan dan memimpin umat Israel keluar dari perbudakan Mesir. Musa adalah Pribadi yang berkenan kepada Tuhan sehingga dipilih untuk menjadi pemimpin Israel yang besar sepanjang sejarah. Musa adalah pribadi yang memiliki hubungan yang dekat dengan Tuhan. Begitu dekatnya hubungan Musa dengan Tuhan sehingga ia bisa mendengar suara Tuhan. Namun, tidak hanya dengan Tuhan, Musa juga memiliki hubungan yang dekat dengan saudara-saudaranya, keluarganya. Dalam kemipimpinannya Musa mampu mendelegasikan tugas kepada orang lain. Ia juga memiliki sifat konfrontasi (Kel 32:19-2), yang kadangkala diperlukan dalam kepemimpinan, terutama dlm mengoreksi yang salah. Dalam tugas ini penulis akan membahas dua poin besar yaitu pertama sejarah panggilan Musa, yang kedua studi kepemimpinan Musa.

\section{METODE}

Penelitian ini menggunakan pendekatan kualitatif yang mengkaji kepemimpinan Musa dari sudut pandang iman Kristen. Penelitian ini melakukan kajian teologis yang bersifat tematik melalui literatur-literatur terkait (literature research) dan mengolah serta menyajikannya secara deskriptif sehingga memghasilkan karya tulis yang dapat dicerap dan diterapkan bagi kehidupan di masa kini, utamanya dalam bidang kepemimpinan Kristen.

\section{HASIL DAN PEMBAHASAN}

\section{Panggilan dan Tugas Musa}

Ketika Musa membunuh orang Mesir karena memukul orang Ibrani, itu adalah usaha yang dilakukan Musa untuk membela bangsanya dari penindasan Mesir, namun 
gagal karena hanya usahanya sendiri dan bukan atas perintah Allah. Namun pada waktu yang ditentukan Allah Musa dipanggil untuk menebus bangsa dengan cara dan kuasa Allah. Memang usaha Musa adalah benar untuk membela bangsa itu, akan tetapi bukan atas perintah Allah maka pada akhirnya gagal atau sia-sia. Tempat awal perjumpaan Musa dengan Allah adalah di gunung Horeb atau yang disebut gunung Allah.

Berkaitan dengan gunung Horeb dan gunung Sinai, Pfeiffer menjelaskan bahwa Horeb disebut sebagai gunung Allah berdasarkan intuisi. Di masa Perjanjian Lama Horeb dan Sinai dipakai sebagai istilah-istilah yang artinya sama. Mengetahui secara pasti tempat Musa berjumpa dengan Allah di antara sekian banyak puncak tersebut, yang tertinggi mencapai 8000 kaki, tidaklah mungkin. Tradisi, yang usianya paling sedikit 1800 tahun, yang menyebutkan sebuah puncak sebagai Jebe Musa, "gunung Musa" pastilah memiliki alasan tertentu, dan puncak yang dinamakan Horeb pasti terletak dekat "gunung" tersebut. ${ }^{1}$ Pada saat Musa menggembalakan kambing domba ayah mertuanya Yitro dekat kaki Sinai, maka tampaklah kepada Musa api membakar semak duri, namun semak duri itu tidak terbakar.

Sebagaimana bangsa Israel tidak habis binasa dalam dapur api penindasan bangsa Mesir, demikian juga semak itu menyala namun tidak terbakar, sebab ada di situ. Sebelum Musa dipanggil Tuhan untuk membebaskan umat Israel, Allah telah memperhatikan penderitaan yang dialami oleh umat-Nya di tanah Mesir. Allah sendirilah yang menjadi penebus bangsa-Nya melalui perantaraan Musa. Tujuan Allah membebaskan umat-Nya adalah untuk mendiami tanah yang berlimpah susu dan madu yaitu tanah Kanaan. Susu dan madu melambangkan kesuburan dan kelimpahan yang besar. Ketika Allah memberikan tugas atau misi yang besar itu kepada Musa, Musa sempat berargumen dengan Allah bahwa ia bukan orang yang pandai bicara, bukan orang yang pantas untuk menjalankan misi itu.

Musa ragu akan dirinya, Musa merasa bahwa dirinya tidak layak untuk menghadap Firaun, Allah menjawab "bukankah Aku menyertai engkau? Inilah tanda bagi mu bahwa Aku yang mengutus engkau: apabila engkau telah membawa bangsa itu keluar dari tanah mesir, maka kamu akan beribadah kepada-Ku di gunung ini, Kel 3: 12”. Sesungguhnya, banyak orang yang layak untuk diutus kepada Firaun, mengapa Allah memilih Musa? Karena Allah sejak semula memilih dan membentuknya menjadi seorang pemimpin, sehingga ketika tiba waktunya Musa tinggal diutus.

\section{Pengungkapan Nama Allah}

Selain Musa keberatan karena dirinya tidak pandai bicara, namun keberatan yang paling utamanya adalah ketidakselarasan antara pekerjaan dan besarnya misi yang harus dilaksanakannya. Musa berkata kepada Allah; "siapakah aku ini sehingga aku yang akan menghadap Firaun? Namun disitu Allah menjanjikan tanpa syarat bahwa Allah sendirilah yang akan menyartai Musa (Kel 3:11-12). Musa terus mengajukan keberatan kepada Allah

\footnotetext{
${ }^{1}$ Charles F. Pfeiffer, “Keluaran,” in Tafsiran Alkitab Wicllffe Volume 1, 2004, 162.
} 
bahwa orang Israel akan bereaksi keras terhadap tugas yang akan diberikan kepadanya. Lasor, Hubbard dan Bush menjelaskan lebih lanjut tentang masalah ini sebagai berikut:

"tetapi apabila aku mendapatkan orang Israel dan berkata kepada mereka: Allah nenek moyang mu telah mengutus aku datang kepadamu, dan mereka bertanya kepada ku: bagaimana tentang nama-Nya? Apakah yang harus aku jawab kepada mereka?" (13), jawaban Allah dinyatakan tiga kali dalam bentuk yang agak berbeda: " AKU ADALAH AKU... beginilah kau katakan kepada orang Israel itu: AKU telah mengutus aku kepadamu ...TUHAN, Allah nenek moyangmu, Allah Abraham, Allah Isak dan Allah Yakub, telah mengutus aku kapadamu: itulah nama$\mathrm{Ku}$ untuk selama- lamanya dan itulah sebutanKu turun temurun" (14-15). ${ }^{2}$

Dengan menanyakan nama Allah apakah Musa menganggap bahwa orang Israel memang ingin mencari keterangan yang sesungguhnya? Apakah orang Israel telah melupakan atau tidak pernah mengetahui nama Allah yang sebenarnya? Dalam hal ini untuk memahami pertanyaan Musa adalah perlu diketahui bahwa dalam Perjanjian Lama nama bukanlah semata-mata untuk membedakan seseorang dari yang lain tetapi berkaitan erat dengan keberadaan orang tersebut. Nama seseorang mewakili dan menyatakan sifat maupun kepribadiannya. Jadi Musa sebenarnya bertanya tentang bagaimana hubungan Allah dengan umat-Nya.

Jawaban Allah yang biasanya diterjemahkan "AKU adalah AKU," bernada seolaholah mengelak dan tidak mau menjawab pertanyaan Musa. Tetapi dalam Keluaran 3:15 Allah mengungkapkan nama-Nya Yhwh, yang disebutkan dalam ayat 14. Konteks keseluruhan khususnya pertanyaan Musa, menanyakan denga tegas bahwa Allah selalu menyatakan diri dan tidak pernah menyembunyikan diri-Nya. "AKU adalah AKU" nama ini Allah sendiri yang memberikan kepada Musa untuk diberitahukan kepada orang Israel ketika Musa datang membebaskan bangsa itu. Sebenarnya Allah mengatakan kepada Musa bahwa Allah ingin kenal sebagai Allah yang maha hadir dan aktif.

Dalam nama Allah yang dalam teks aslinya YHWH terkandung janji bahwa kehadiran Allah sendiri bersama umat-Nya hari lepas hari. Nama Allah itu mengungkapkan perhatian-Nya yang setia, bersama kerinduan untuk menebus umat-Nya dan selalu ingin hidup dalam persekutuan dengan umat-Nya. Sama halnya seorang ayah yang selalu rindu dan ingin hidup dalam kerukunan dengan keluarganya. Seorang ayah jasmani menunjukan kasihnya yang besar kepada keluarganya, tapi Allah lebih dari seorang ayah jasmani. Oleh sebab itu, sekali pun orang Israel tegar tengkuk namun Allah tetap mengasihi bangsa itu dengan tulus.

\section{Allah Menyertai Musa}

\footnotetext{
${ }^{2}$ W. S. Lasor, D. A. Hubbard, and F. W. Bush, Pengantar Perjanjian Lama 1 (Jakarta: BPK Gunung Mulia, 1993).194
} 
Dalam poin sebelumnya Allah telah mengungkapkan nama-Nya kepada Musa, namun dalam poin ini Musa masih terus menyampaikan keberatannya terhadap panggilan Allah. Dalam pasal 4 Musa mengakui bahwa dirinya tidak pandai berpidato dan berat lidah. Allah berjanji akan menyertai lidahnya dan mengajarkan semua apa yang akan dibicarakannya ketika menghadap Firaun. Ketika semua keberatan Musa dijawab oleh Allah dengan janji penyertaan dan kuasa Allah yang penuh kemurahan, maka di situlah waktu Musa untuk mengambil keputusan. Musa sedikit berargumen lagi dengan Allah bahwa Allah harus mengutus orang lain yang lebih pandai dan lebih pintar darinya, tetapi Allah tidak menerima apa yang disampaikan Musa.

Dapat dikatakan bahwa Musa orang yang keras kepala dan tidak mendengar apa yang Allah perintahkan, namun pada akhirnya Musa menerima Misi dan tugas yang Allah berikan kepadanya. Dalam menjalankan misi dan tugas itu Musa tidak berjalan sendiri tetapi juga Harun beserta dengannya. Musa berperan seperti Allah untuk memberi tugas dan pesan kepada Harun sebagai juru bicara. Harun menjadi juru bicara, oleh karena itu, Harunlah yang menyampaikan tujuan dari misi itu kepada Firaun. Musa ditugaskan sebagai utusan dengan cara yang khas untuk panggilan menjadi seorang nabi:

"Adapun TUHAN sudah berfirman kepada Musa di midian: Kembalilah ke Mesir . . .Maka engkau harus berkata kepada Firaun: beginilah firman TUHAN: Israel adalah anakKu, anakKu yang sulung; sebab itu Aku berfirman kepadamu: Biarkanlah anakKu itu pergi, supaya ia beribadah kepadaKu"” (ay. 19- 23) dan tugas itu dilaksanakan: "Musa dan Harun pergi menghadap Firaun, lalu berkata berkata kepadanya: Beginilah firman TUHAN, Allah Israel, 'Biarkanlah umatKu pergi “" $(5: 1) .^{3}$

\section{Kepribadian Musa}

Musa adalah salah seorang pemimpin besar dalam Perjanjian Lama. Sepak terjangnya dalam dunia kepemimpinan diperolehnya dari setiap pengalaman hidup yang menuntutnya untuk selalu belajar. Pengalaman hidup Musa menjadi alat Tuhan untuk membentuk dan menyatakan rencana-Nya kepada Musa, bahwa Ia bermaksud menjadikan Musa seorang pemimpin besar yang mengantarkan bangsa Israel keluar dari tanah perbudakan. Allah memilih Musa menjadi pemimpin bukan hanya karena kecakapannya; Allah juga bermaksud memperlengkapi Musa dengan semangat tidak mudah menyerah, syarat penting yang dibutuhkan oleh setiap pemimpin besar.

Musa merupakan tipologi Kristus dalam Perjanjian Lama, Yesus selalu berada dalam kerumunan orang, orientasinya senantiasa mengarah kepada belas kasihan terhadap orang banyak, segala sesuatu yang Yesus lakukan semuanya untuk khalayak ramai. ${ }^{4}$

\footnotetext{
${ }^{3}$ Lasor. D. A. Hubbard, Pengantar Perjanjian Lama 1 (Jakarta: BPK Gunung Mulia, 1993).

${ }^{4}$ Fredy Simanjuntak, "Kecerdasan Emosi Pemimpin Sebagai Tolok Ukur Gereja Yang Sehat," Real Didache 2, no. 1 (2017): 29-53.
} 
Musa benar-benar belajar dari masa lalunya. peristiwa buruk pasti memberikan hikmah dan pelajaran yang berharga bagi Musa. Paling tidak, keburukan atau kegagalan yang dilihat atau dialaminya telah menambah satu ilmu tentang cara-cara mengatasinya. Gambar diri Musa yang salah, perasaan tidak berharga dan tidak berdaya dapat sembuh dan pulih kembali dengan menerima diri apa adanya (penerimaan diri tanpa syarat), dengan sungguh-sungguh mengampuni (memberi pengampunan tanpa syarat), penghargaan diri yang benar yaitu dengan melihat diri segambar dan serupa dengan Allah (apa kata Alkitab tentang kita). ${ }^{5}$

\section{Memiliki hubungan dengan Allah}

Musa dikenal sebagai orang yang sangat dekat dengan Allah. Bahkan, Allah menyatakan bahwa hanya kepada Musalah Allah berbicara berhadap-hadapan seperti seorang sahabat tanpa ada hal yang ditutup-tutupi. Musa adalah orang pilihan Allah, Musa menjadi pemimpin atas orang Ibrani atau orang Israel bukan dipilih dan diangkat oleh manusia. Raja Saul menjadi Raja pertama Israel diangkat oleh Samuel atas permintaan orang Israel, tetapi Musa menjadi pemimpin diangkat dan ditujuk langsung oleh Allah sendiri. Musa sejak kecil dibesarka, dididik di lingkungan istana. Pendidikan di istana Firaun saja tidak memadai untuk memperlengkapi Musa bagi pekerjaan Tuhan. Menyendiri bersama Allah dan empat puluh tahun pembimbing kambing domba di padang gurun juga diperlukan untuk mempersiapkannya bagi tugas mendatang untuk mengembalakan bangsa Israel melalui padang gurun. ${ }^{6}$

Dalam sejarah Alkitab hanya Musa satu-satunya nabi yang berbicara langsung atau berhadapan muka dengan muka dengan Tuhan, Berarti Musa spesial di mata Tuhan. Musa adalah pemimpin yang berhasil mengeluarkan bangsanya sendiri atau bangsa Ibrani dari perbudakan Mesir. Musa berhasil bernegosiasi dengan Firaun dan Tuhan mengeraskan hati Firaun agar Musa bekerja lebih keras lagi supaya bangsa itu bisa keluar dari Mesir. Tujuan lain dari Allah untuk mengeraskan hati Firaun adalah agar orang Mesir atau pun Firaun tahu bahwa Allah Israel adalah Allah yang benar dan Allah yang penuh kuasa. Hubungan Musa dengan Allah begitu erat sehingga ketika Allah memerintahkan Musa, Musa langsung mendengar suara Tuhan.

Pertemuan Musa dengan Allah membuat dia tanggap terhadap kehendak Allah dalam hidupnya. Musa mengetahui bahwa membawa umat Israel keluar dari Mesir bukanlah sebuah pekerjaan, melainkan sebuah panggilan dalam hidupnya. Musa mematikan dirinya saat melihat semak belukar yang menyala-nyala dan itulah awal pekerjaan Allah. Waktu yang dihabiskannya bersama dengan Tuhan membawanya pada pemahaman akan Allah. Menurut Keluaran 33:18, keakraban ini membimbing dia untuk berseru di atas gunung, Musa berkata agar Allah "Perlihatkanlah kiranya kemuliaan-Nya

\footnotetext{
${ }^{5}$ Ibid.

${ }^{6}$ C. Stamp Donal, Alkitab Penuntun Hidup Berkelimpahan (Malang: Gandum Mas, 1991).98
} 
kepadanya." Hubungan inilah yang meyakinkannya bahwa walaupun Musa menghadapi perlawanan besar dari Firaun, Allah akan memberikan kemenangan ketika Musa mengikuti panggilan Allah di dalam hidupnya. Walaupun umat Israel meragukan Musa, Musa mengetahui bahwa Allah akan menguatkannya dengan kemampuan, talenta, dan kecakapan yang penting untuk memenuhi panggilannya.

\section{Pola Pendelegasian}

Musa adalah pemimpin yang sangat dikagumi dan sangat diandalkan oleh umat Israel, karena melalui Musa umat Israel bisa keluar dari tanah perbudakan. Sekali pun umat Ibrani atau orang Israel sempat bersungut-sungut kapada Tuhan karena harus melewati padang gurun yang luas, namun secara perlahan-lahan bangsa itu mulai percaya bahwa Tuhan sanggup memimpin dan menuntun bangsa itu sampai kepada tanah perjanjian. Musa di dalam menjalankan tugas dan misi yang Tuhan berikan kepadanya, Musa tidak bekerja sendiri namun ada pendelegasian tugas kepada orang- orang yang Musa anggap sanggup mengemban tugas yang akan diberikan olehnya.

Pengertian delegasi adalah proses penyerahan tanggung jawab dan wewenang kepada seseorang. Musa menyangka akan memimpin suatu pasukan yang penuh kemenangan ke tanah perjanjian. Sesungguhnya, bangsa itu harus bertindak seperti bayi rohani, dan Musa merasa bahwa beban itu terlalu besar atau terlalu berat baginya. Maka Allah mengambil sebagian Roh yang ada pada Musa dan menaruh kepada tujuh puluh tuatua Israel untuk menjalankan tugas yang diberikan padanya (Bil. 16-17). Demikianlah Musa tahu bahwa denga kuasa Roh Allah Musa dapat menghadapi tantangan yang dari setiap tugas yang dibebankan oleh Allah kepadanya, karena beban itu tidak bisa ditanggung oleh kekuatan sendiri. ${ }^{7}$ Demikian juga Paulus dalam suratnya kepada Titus; "supaya engkau mengatur apa yang masih perlu diatur dan supaya engkau menetapkan penatuapenatua di setiap kota, seperti yang ku telah pesankan kepadamu (Tit. 1:5)."8

Meskipun Paulus tidak membuat suatu tugas tentang sebuah perencanaan, tetapi secara implisit baik di dalam setiap pola berpikir maupun gerak-geriknya selalu menampakan pola itu dalam suratnya. Jadi pola Paulus dalam mendelegasikan tugas sama dengan pola yang dibuat oleh Musa. Salah satu pola pendelegasian yang benar adalah pola pendelegasian kepemimpinan Musa (Bil. 11:10-15). Pendelegasian yang benar adalah akan didelegasikan kepada orang yang benar pula. Seorang pemimpin yang baik selalu menyadari kesanggupan atau keterbatasan dan kelemahannya juga meyakini kesanggupan dan keterbatasan dari orang yang dipimpinnya. Musa selalu mengalami kesulitan dalam kepemimpinannya karena Musa mau kerja sendiri tugas-tugas yang bisa dilakukan oleh bawahannya dan ternyata bisa gagal apa yang dilakukannya.

\footnotetext{
${ }^{7}$ Ibid.

${ }^{8}$ P. Octavianus, Manajemen Dan Kepemimpinan Menurut Wahyu Allah (Malang: Gandum Mas, 1994).17
} 
Musa menyadari kegagalannya ketikanya melakukan pekerjaan yang Tuhan berikan kepadanya dan mengatakan bahwa dirinya tidak sanggup memikul tanggung jawab seluruh bangsanya (ay. 14). Memang Musa seorang pemimpin yang penuh pengabdian, kendati demikian kepemimpinannya lemah. Sebelum Musa mendapat kritik dari mertuanya yaitu Yitro bahwa tidak baik kalau Musa melakukan pekerjaan yang berat sendirian, akhirnya Musa mulai melangkah dalam pendelegasiannya. Pendelegasian memang merupakan suatu faktor penting yang menentukan keberhasilan kepemimpinan atau pelayanan. Pendelegasian memungkinkan seseorang pemimpin dapat berbuat banyak hal bagi dan melalui banyak orang. ${ }^{9}$ Itulah yang banyak dilakukan oleh para pendahulu iman, termasuk para misionaris di masa lalu yang berhasil dalam pelayanan dan kepemimpinannya. Nomensen misalnya, seorang misionaris Jerman yang sangat berhasil dalam pelayanannya kepada orang Batak, telah menerapkan pola yang sama, yaitu pendelegasian. Salah satu kunci sukses kepemimpinan dan pelayanannya adalah dia secara aktif melibatkan umat dalam pelayanan dan mempraktekkan pola pemuridan untuk membentuk para pemimpin Kristen dari orang lokal yang ditujukan untuk membantunya mengelola pelayanan dan memberitakan Injil. ${ }^{10}$ Akibatnya, pelayanannya berkembang dan kepemimpinannya dikenang.

\section{Penjabaran Tugas}

Penjabaran tugas sangat penting dilakukan dalam sebuah kepemimpinan supaya tugas-tugas yang harus dijalankan dalam lebih terarah dan efisien dan efektif. Penjabaran tugas membuat organisasi atau individu bekerja dengan maksimal. Definisi penjabaran tugas ialah "sebuah Rincian tentang apa yang harus dicapai; cara pencapaian dan penjelasan tentang otoritas dan akuntabilitas yang diberikan kepada seseorang di dalam posisinya di sebuah organisasi". ${ }^{11}$ Pada dasarnya penjabaran adalah garis- garis besar dari apa yang diharapkan dari seseorang dalam melaksanakan tugas tertentu, dituangkan secara tertulis menjadi suatu penjabaran tugas secara tertulis. Bukan masalah siapa yang melaksanakan tugas itu tetapi berpusat kepada apa yang harus dicapai. Penjabaran tugas menolong organisasi maupun individu untuk mengukur sendiri sampai sejauhmana penampilannya dalam melaksanakan tugas yang harus dijalankannya.

Penjabaran tugas juga menolong dalam menghubungkan suatu tugas dengan tugas yang lain. Pemimpin memberi batas-batas antara pekerjaan dan bagaimana seorang petugas atau pejabat melihat tugasnya sebagai bagian dari keseluruhannya. Demikian dengan kepemimpinan Musa bagaimana Musa menjalankan penjabaran tugasnya setelah mendapatkan teguran dari mertuanya. Tugas utama dari Musa adalah mewakili umat di hadapan Allah. Setiap ada keluhan dari bangsa Israel atau pun ketika Tuhan mau

${ }^{9}$ Ibid.

${ }^{10}$ Irfan Feriando Simanjuntak, "Kekristenan Batak Dan Tantangan Penjangkauannya Di Batam," Real Didache 1, no. 1 (2016): 23-34.

${ }^{11}$ Moranda Girsang, Diktat Kuliah: Kepemimpinan Gereja, 2014. 
memberikan arahan kepada Musa, Musalah yang mejadi parantara antara umat dengan Tuhan. Mengerjakan ketetapan dan keputusan yang besar yang Tuhan berikan kepanya. Tugas besar adalah bagian Musa, sedangkan tugas kecil adalah orang- orang yang diberikan kepercayaan oleh Musa.

\section{KESIMPULAN}

Kesimpulan untuk studi kepemimpinan Musa ialah jawaban atas kosongnya kepemimpinan yang melanda gereja dan dunia sekuler pada saat ini dapat ditemukan melalui studi kepemimpinan Musa di dalam Alkitab, sebagai seorang tokoh pemimpin yang benar- benar memimpin. Musa seorang pemimpin yang dipakai oleh Tuhan dalam segala aspek hidupnya Musa disiapkan menjadi pemimpin besar yang mengeluarkan umat Israel dari Mesir.

Musa merupakan model kepemimpinan yang berharga karena Musa mempunyai corak kepemimpinan kharismatis, administratif, dan penyelesai konflik. Studi yang menyeluruh tentang temperamen Musa, hukum kepemimpinannya, kesempatankesempatan, dan ancaman-ancaman yang dihadapinya, akan berguna untuk semua pemimpin, baik pemimpin sekuler maupun pemimpin Kristen (rohani atau pun pemimpin gereja).

\section{KEPUSTAKAAN}

Charles F. Pfeiffer. "Keluaran.” In Tafsiran Alkitab Wicllffe Volume 1, 162, 2004.

Donal, C. Stamp. Alkitab Penuntun Hidup Berkelimpahan. Malang: Gandum Mas, 1991. Girsang, Moranda. Diktat Kuliah: Kepemimpinan Gereja, 2014.

Hubbard, Lasor. D. A. Pengantar Perjanjian Lama 1. Jakarta: BPK Gunung Mulia, 1993. Lasor, W. S., D. A. Hubbard, and F. W. Bush. Pengantar Perjanjian Lama 1. Jakarta: BPK Gunung Mulia, 1993.

Octavianus, P. Manajemen Dan Kepemimpinan Menurut Wahyu Allah. Malang: Gandum Mas, 1994.

Simanjuntak, Fredy. "Kecerdasan Emosi Pemimpin Sebagai Tolok Ukur Gereja Yang Sehat." Real Didache 2, no. 1 (2017): 29-53.

Simanjuntak, Irfan Feriando. "Kekristenan Batak Dan Tantangan Penjangkauannya Di Batam." Real Didache 1, no. 1 (2016): 23-34. 